\title{
Microstructure, friction and wear analysis of thermoplastic based composites with solid lubricant
}

\author{
Basma Ben Difallah ${ }^{1,2,4}$, Mohamed Kharrat ${ }^{1,3, a}$, Maher DammaK ${ }^{1,3}$ and Guy Monteil ${ }^{4}$ \\ 1 Laboratoire des Systèmes Électromécaniques, École Nationale d'Ingénieurs de Sfax, Route de Soukra km 3,5, BP 1173, \\ 3038 Sfax, Tunisia \\ 2 Institut Supérieur des Sciences Appliquées et de la Technologie de Gafsa, Campus Universitaire Sidi Ahmed Zarrouk, \\ 2112 Gafsa, Tunisia \\ 3 Institut Préparatoire aux Études d'Ingénieurs de Sfax, Rte Menzel Chaker Km 0,5, BP 1172, 3018 Sfax, Tunisia \\ 4 Laboratoire FEMTO-ST, École Nationale Supérieure de Mécanique et des Microtechniques, 26 rue de l'Épitaphe, \\ 25030 Besançon, France
}

Received 19 June 2012, Accepted 4 December 2012

\begin{abstract}
Thermoplastic based composites containing different weight fractions of molybdenum disulfide $\left(\mathrm{MoS}_{2}\right)$ solid lubricant were developed by injection molding. Polymethyl methacrylate (PMMA) and polycarbonate $(\mathrm{PC})$ were chosen for the thermoplastic matrices. In order to characterize the interfacial adhesion between the matrices and the filler, we observed the fracture morphologies of selected composites. Micrographs of the fractured surfaces showed removal of $\mathrm{MoS}_{2}$ particles by microcraking as well as the presence of voids in the case of PMMA/MoS 2 composites. These observations were confirmed by complementary images obtained using the X-ray tomography. The addition of an appropriate coupling agent may improve the adhesion between the $\mathrm{MoS}_{2}$ particles and the polymer matrix. Tribological behavior of the composites was also investigated using a ball-on-flat microtribometer with a high chromium steel ball antagonist. It was found that the addition of $\mathrm{MoS}_{2}$ particles didn't improve the tribological performance of the composite in the case of PMMA matrix unlike the case of PC matrix where the friction coefficient was considerably reduced.
\end{abstract}

Key words: Composite / thermoplastic / $\mathrm{MoS}_{2}$ / solid lubricant / interface / adhesion / friction / wear

\section{Introduction}

In the last decade, research activities in the field of thermoplastic composites have moved towards the progress of "cost performance" engineering materials. Engineering thermoplastic composites are getting significant attention due to increased energy assessment. The advantages in terms of recyclability and lightweight together with the regulatory norms are covering increasing applications of engineering thermoplastic composites in the infrastructure applications, automotive, electrical, electronics... Indeed, it was claimed that the tribological behavior of engineering thermoplastic can be improved by filling them with inorganic particulate compounds or fibers [1-5]. In particular, polymers and coatings filled with solid lubricants have been extensively studied because of the increasing industrial and military applications [6-9]. In fact, solid lubricants such as polytetrafluoroethylene (PTFE), $\mathrm{MoS}_{2}$ and graphite have

\footnotetext{
${ }^{a}$ Corresponding author: mohamed.kharrat@ipeis.rnu.tn
}

excellent anti-friction and wear-resistance performances. They are commonly used to solve tribological problems in applications where fluid lubricants are ineffective and undesirable [10-13]. Solid lubricants have been originally developed for aerospace applications and are currently widely used in many fields [13-17].

In particular, $\mathrm{MoS}_{2}$ is between the most promising and important solid lubricants. It offers a remarkable effect in delivering the tribo-active components to the contacting surfaces. In fact, its hexagonal lamellar structure facilitates easy glide between the S-Mo-S layers which results in a very low coefficient of friction $[18,19]$. Nevertheless, a highly exothermic oxidation reaction may form molybdenum oxide $\left(\mathrm{MoO}_{3}\right)$ at temperatures exceeding $350{ }^{\circ} \mathrm{C}[20,21]$. Bahadur and Gong [18] reported that wear was reduced considerably by the addition of $\mathrm{MoS}_{2}$ to PTFE, polyamide 66 (PA 66) and polyimide (PI). They also reported that the $\mathrm{MoS}_{2}$ fillers proportion affects the wear resistance of composites. In fact, the wear rate of PA decreased initially with the increase in $\mathrm{MoS}_{2}$ content. 
The lowest wear rate value was obtained with an optimum content about 15 to $20 \%$ in weight of $\mathrm{MoS}_{2}$. Beyond this mass ratio, the wear rate increased again. Pettarin et al. [19] found that $\mathrm{MoS}_{2}$ improved the sliding and abrasive wear performance of High Molecular Weight Polyethylene (HMWPE) and High Density Polyethylene (HDPE). The authors found again an optimum content of $\mathrm{MoS}_{2}$ to be about $10 \%$ in weight. Bijwe et al. [22] studied the effect of incorporation solid lubricants and glass fibers on the adhesive and abrasive wear performance of a polyethersulphone matrix. They reported that the addition of $2 \%$ of PTFE or $\mathrm{MoS}_{2}$ with fibers influenced the performance in a beneficial manner in the case of adhesive wear mode and in a detrimental manner in the case of abrasive wear mode. On the contrary, Bijwe et al. found that the addition of $\mathrm{MoS}_{2}$ to PTFE matrix does not impart a good wear behavior [23]. This result is obtained because the $\mathrm{MoS}_{2}$ filler didn't contribute in carrying the load, thus, it enhanced the wear values. Likewise, Liu et al. reported that the incorporation of $\mathrm{MoS}_{2}$ fillers to PA6 matrix was not very effective in reducing friction and contributed to the increase in wear [24].

In the present work, first we aim to evaluate the adhesion and cohesion properties of $\mathrm{MoS}_{2}$ fillers incorporated to two different thermoplastic matrices, the commercial PMMA and PC grades. The choice of these two amorphous thermoplastics was attributed to their high friction and large wear rate. In the second hand, our purpose consists in evaluating the actual capability of $\mathrm{MoS}_{2}$ in improving the tribological properties of the two polymers. SEM investigations on cryofractured samples of the two thermoplastic polymers with different weight fractions of $\mathrm{MoS}_{2}$ were done. Besides, sliding tests and microscopical techniques were combined to elucidate the role of the fillers in the tribological behavior of the two considered thermoplastic/ $\mathrm{MoS}_{2}$ composites.

\section{Experimental set up}

\subsection{Materials}

Commercial PMMA and PC thermoplastic polymers were used as the matrices of the composites. The PMMA pellets were provided from $R \ddot{O} H M G m b H$ Chemische Fabrik of Germany (1.19 g.cm ${ }^{-3}$ density, 1.8 g/10 min IF). The PC granules were purchased from Macrolon ${ }^{\circledR}$ of Bayer, (1.02 g.cm ${ }^{-3}$ density, $38 \mathrm{~g} / 10 \mathrm{~min}$ IF). $\mathrm{MoS}_{2}$ powder (6 $\mu \mathrm{m}$ average size, 5.06 g.cm ${ }^{-3}$ density) with $95 \%$ purity was provided by Aldrich Chemistry (Sigma-Aldrich) (Fig. 1). The $\mathrm{MoS}_{2}$ fillers content in the composites was varied from 2 to $10 \%$ in weight (wt \%).

\subsection{Composites preparation}

The apparatus used to disperse the solid lubricant fillers within the polymer matrices was a Brabender ${ }^{\circledR}$. Plastograph EC W50EHT internal mixer coupled with a

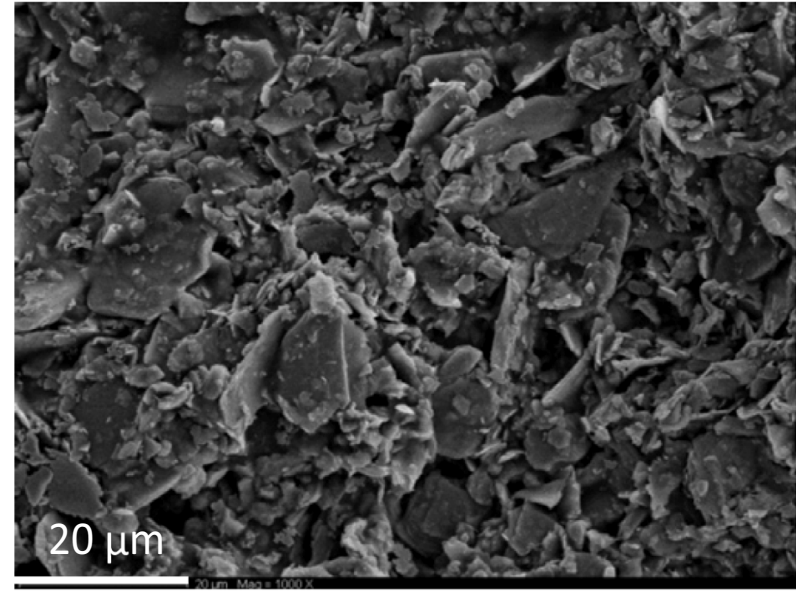

Fig. 1. SEM image of $\mathrm{MoS}_{2}$ powder, as supplied.

Table 1. Mixing parameters of PMMA and PC composites [25].

\begin{tabular}{cccc}
\hline $\begin{array}{c}\text { Mixing } \\
\text { parameters }\end{array}$ & $\begin{array}{c}\text { Time } \\
(\mathrm{min})\end{array}$ & $\begin{array}{c}\text { Temperature } \\
\left({ }^{\circ} \mathrm{C}\right)\end{array}$ & $\begin{array}{c}\text { Rotation speed } \\
(\mathrm{rpm})\end{array}$ \\
\hline $\begin{array}{c}\mathrm{PMMA} / \mathrm{MoS}_{2} \\
\text { composites }\end{array}$ & 20 & 200 & 120 \\
\hline $\mathrm{PC} / \mathrm{MoS}_{2}$ & 40 & 180 & 40 \\
composites & & & \\
\hline
\end{tabular}

mixer head with controlled rotation speed and temperature. In-situ torque measurement allows the control of the fillers dispersion into the matrix and its uniformity. After complete homogenization, the rotors were stopped and the blends were removed and sheeted through a laboratory mill. Then the blends were injection molded using an ARBURG Allrounder $220 \mathrm{~S}$ injection molding machine. For each of the two considered composites, the mixing parameters are given in Table 1 while the injection parameters are given in Table 2 .

\subsection{Microstructural characterization}

\subsubsection{Fractography analysis}

Fractography analysis consists in the examination of fractured surfaces to deduce information upon the cohesion of the materials. This technique underpins material development and provides an insight into the physical processes by which composites are damaged and failed. Factors such as temperature, moisture, loading rate and, in the case of thermoplastic matrices, degree of crystallisation can have a considerable effect on the fracture morphology $[26,27]$. In addition to these factors, the composite fracture morphology is directly affected by the mechanical strength of the filler/matrix interface. Fractography has proved to be a powerful and reliable tool for the composite engineer, and is a vital technique for the overall development of composite structures [28]. In our study, the fractured samples were gold-coated and examined with a SEM (JEOL JSM 6400 F). 
Table 2. Injection molding parameters of PMMA and PC composites.

\begin{tabular}{cccc}
\hline $\begin{array}{c}\text { Injection molding } \\
\text { parameters }\end{array}$ & $\begin{array}{c}\text { Barrel temperature } \\
\left({ }^{\circ} \mathrm{C}\right)\end{array}$ & $\begin{array}{c}\text { Injection pressure } \\
(\mathrm{MPa})\end{array}$ & $\begin{array}{c}\text { Injection speed } \\
\left(\mathrm{mm} \cdot \mathrm{s}^{-1}\right)\end{array}$ \\
\hline $\begin{array}{c}\text { PMMA/MoS } \\
\text { composites }\end{array}$ & 250 & 120 & 20 \\
\hline $\begin{array}{c}\text { PC/MoS } \\
\text { composites }\end{array}$ & 290 & 75 & 35 \\
\hline
\end{tabular}

Table 3. Friction test conditions for PMMA and PC composites.

\begin{tabular}{cccccc}
\hline Test conditions & $\begin{array}{c}\text { Ball diameter } \\
(\mathrm{mm})\end{array}$ & $\begin{array}{c}\text { Normal load } \\
(\mathrm{N})\end{array}$ & $\begin{array}{c}\text { Displacement magnitude } \\
(\mathrm{mm})\end{array}$ & $\begin{array}{c}\text { Hertz pressure } \\
(\mathrm{MPa})\end{array}$ & Number of cycles \\
\hline $\begin{array}{c}\text { PMMA/MoS } \\
\text { composites }\end{array}$ & 5 & 0.5 & 1 & 46 & 1000 \\
\hline $\begin{array}{c}\text { PC/MoS } \\
\text { composites }\end{array}$ & 19 & 5 & 2 & 41 & 10000 \\
\hline
\end{tabular}

\subsubsection{X-ray tomography}

$\mathrm{X}$-ray tomography is a non-destructive testing for the study of a wide range of specimens. The internal structure of the sample can be investigated by taking a large number of projection images while rotating the specimen between projections. This set of projections can be recreated into a raw three dimensions volume. One of the most important challenges in X-ray tomography lies within the investigation of this reconstructed volume. A lot of image processing tools are accessible in two dimensions, but porting them to three dimensions volume requires a lot of additional effort [29]. For ease of illustration in this publication, we will only discuss two-dimensional images, however, volumetric information can also be obtained.

\subsection{Friction and wear test}

Friction and wear tests were conducted using a reciprocating ball on flat microtribometer. The composite flat specimens were rubbed against a high chromium steel ball 100Cr6 $(R a=0.12 \mu \mathrm{m})$ under a triangular alternated displacement at $1 \mathrm{~Hz}$ frequency. As illustrated in Table 3, the ball diameter depends on the nature of the composites. Even if the operating conditions are different, contact pressure is almost the same for the two kinds of composite. At least, three friction and wear tests were conducted for each composite. The used microtribometer can be divided into three functional sub-systems. The first one is the mechanical arrangement (measuring head) generating the required contact load (normal load) between the high chromium steel ball and the flat composite sample and allowing the tangential load to be monitored using a piezoelectric sensor. The measuring head is equilibrated by a counterbalancing arm allowing the magnitude of the dead load to be adjusted to very low values. The second sub-system is the micro-displacement arrangement based upon a translation table with a precise linear ball bearing. This table is coupled to a step-by-step motor using a ball screw. The third sub-system is a control and data acquisition unit used for driving the microtribometer and

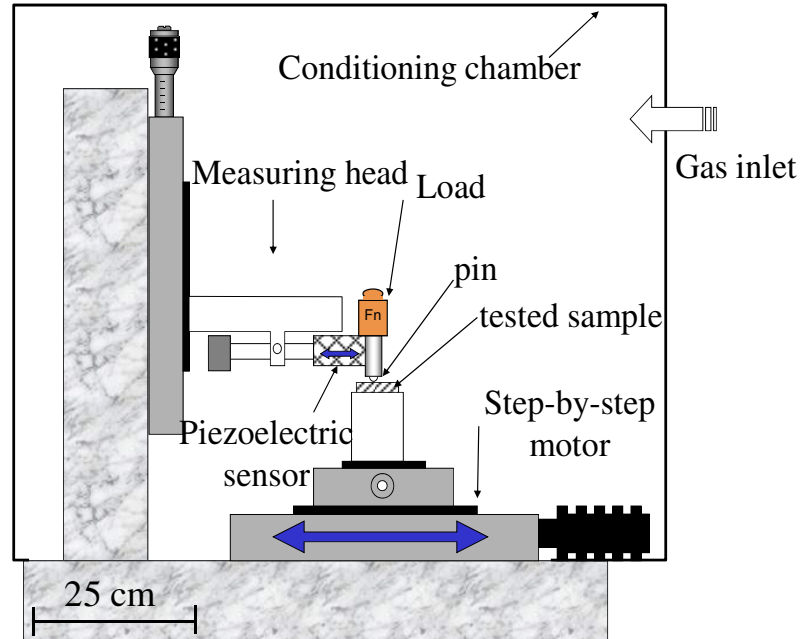

Fig. 2. Schematic representation of the ball on flat microtribometer.

for data acquisition and processing. The treatment of the measurements and the display of the results are performed by PC based software.

The different parts of the microtribometer are shown in Figure 2. All the mechanical elements are fixed on an inertial marble structure, being ungrounded by damping blocks in order to avoid any vibrations or mechanical distortions of the system during the tests. The enclosure is made of PMMA and the regulation of the testing atmosphere is obtained by a gaseous flux. All tests were performed at ambient atmosphere and ambient relative humidity in the order of $55 \%$. Table 3 illustrates friction test conditions for PMMA and PC composites.

\section{Results and discussion}

\subsection{Mixing processing}

The rheograms in Figure 3 show the torque against time results obtained during processing the PMMA 

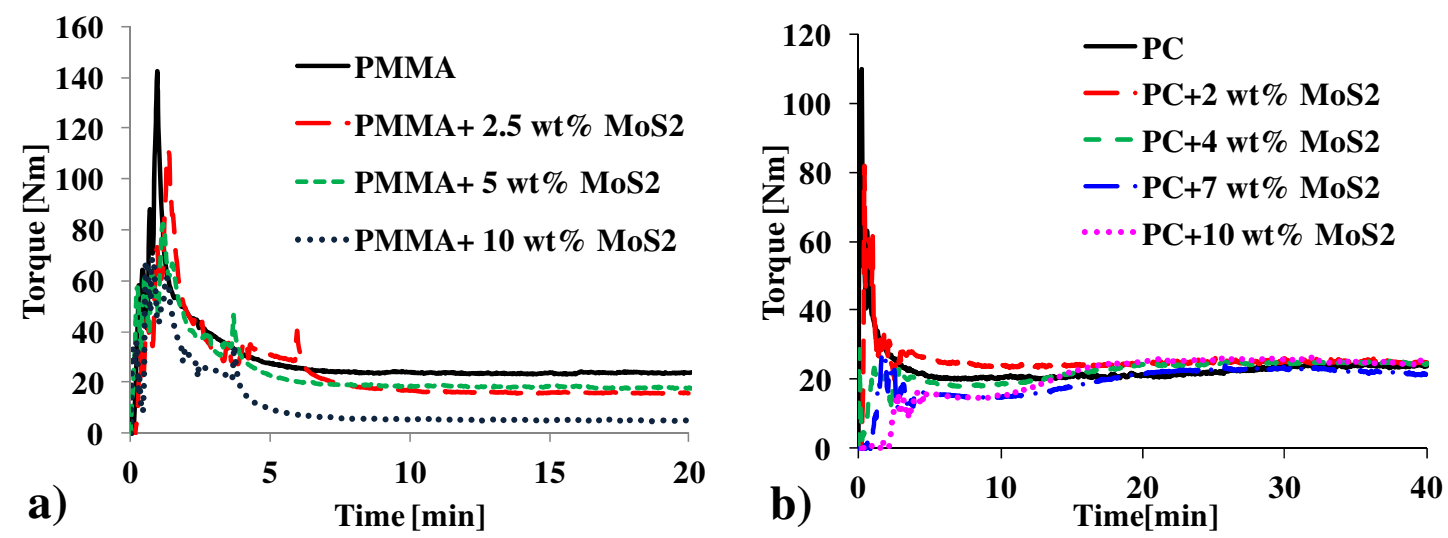

Fig. 3. Torque-time curves for; (a) $\mathrm{PMMA} / \mathrm{MoS}_{2}$ composites and (b) $\mathrm{PC} / \mathrm{MoS}_{2}$ composites.

composites and the $\mathrm{PC}$ composites in the totally filled chamber conditions. In all cases, an initial loading peak was registered just after the rotors were started and reflects the high viscosity of the unmelted thermoplastic polymer. The loading peak decreases as the fillers content increases due to the reduction in the charged weight of the polymer. Composites start to melt under high shear and mixing temperature, which is more than the set temperature, resulting in reduction in the viscosity. As a consequence, the torque undergoes a sudden decrease immediately after the loading peak followed by a subsequent gradual decrease. Few minutes after shearing $(7 \mathrm{~min}$ for PMMA/MoS 2 composites and 20 min for PC/MoS 2 composites), the mixture shows stable torque indicating the completion of melting and almost constant viscosity at fixed mixing conditions [30,31].

\subsection{Microstructure/fracture behavior}

Figure 4 summarizes the SEM images of the fractured surfaces of PMMA/MoS 2 composite specimens. The composites display a two-phase morphology with PMMA continuous phase and a dispersed fillers phase of isolated long and narrow $\mathrm{MoS}_{2}$ particles. PMMA matrix displays rough regions which increase in size with the weight fraction of the solid lubricant fillers. Figures $4 \mathrm{a}$ and b show the composite at $2.5 \mathrm{wt} \% \mathrm{MoS}_{2}$. A gap between the filler and the matrix is seen which corresponds to debonding at the PMMA/MoS 2 interface due to poor adhesion. Apparently, a more pronounced debonding phenomenon is observed for the other filler fractions (Figs. 4c-f). The PMMA/MoS 2 composites exhibit voids which correspond to the location of the extracted filler particles. The voids density increases with the filler's fraction. The filler is pulled from the matrix in order to dissipate the additional fracture energy. Chamis [32] found that the surface morphology of cracks is heavily dependent on the interfacial bonding conditions and results in either cohesive or adhesive failure.

For the $\mathrm{PC} / \mathrm{MoS}_{2}$ composites, the work was focused on the improvement of the interfacial properties between the $\mathrm{MoS}_{2}$ flakes and the PC matrix. Thus, $8 \mathrm{wt} \%$ of Stearic Acid powder (SA) was added to the composite during the mixing process as a coupling agent which could probably increase the polymer- $\mathrm{MoS}_{2}$ interaction [33]. In this case, 2 wt\% of Paraffin Oil (PO) was also added to improve the viscosity of the mixture. Figure 5 compares the fractured surfaces of $\mathrm{PC} / \mathrm{MoS}_{2}$ composites at $10 \mathrm{wt} \%$ of $\mathrm{MoS}_{2}$ with and without coupling agent. With no coupling agent, Figures $5 \mathrm{a}$ and b show the same mechanisms observed in the case of PMMA composites. We clearly see a phase separation between the PC matrix and the fillers as well as the presence of voids. This indicates that the polymer matrix and the $\mathrm{MoS}_{2}$ particles didn't restrain together. Adjunction of coupling agent to the composite improved its adhesion properties (Figs. 5c and $\mathrm{d}$ ). The interfacial interaction between the PC matrix and $\mathrm{MoS}_{2}$ particles was stronger and this would be a reason for the improvement in the mechanical properties of the $\mathrm{PC} / \mathrm{MoS}_{2}$ composites [34]. Furthermore, it seems that composites with coupling agent achieve better fillers distribution.

\subsection{X-ray tomography analysis}

Figures $6 \mathrm{a}$ and b show the reconstructed 2D X-ray tomography images of $\mathrm{PMMA} / \mathrm{MoS}_{2}$ composite at $5 \mathrm{wt} \%$ of $\mathrm{MoS}_{2}$. The black zones in Figure 6 a give idea about the spatial distribution of the solid lubricant particles in the PMMA matrix. It seems that the distribution is homogeneous. The filler particles have different shapes and sizes. In fact, even if the average size of $\mathrm{MoS}_{2}$ particles is around $6 \mu \mathrm{m}$, it can vary from 2 or $3 \mu \mathrm{m}$ to more than $20 \mu \mathrm{m}$. The Figure $6 \mathrm{~b}$ shows the existence of porosity in the composite. The biggest porosities seem to locate preferentially in the particles/matrix interface. This last result is in agreement with the fracture behavior analysis which indicated a poor adhesion between the $\mathrm{MoS}_{2}$ flakes and the PMMA matrix.

\subsection{Friction and wear behaviors of the composites}

Figure 7 compares the friction behavior for PMMA/MoS 2 composites containing different wt\% $\mathrm{MoS}_{2}$. It can be seen that the adjunction of $\mathrm{MoS}_{2}$ 

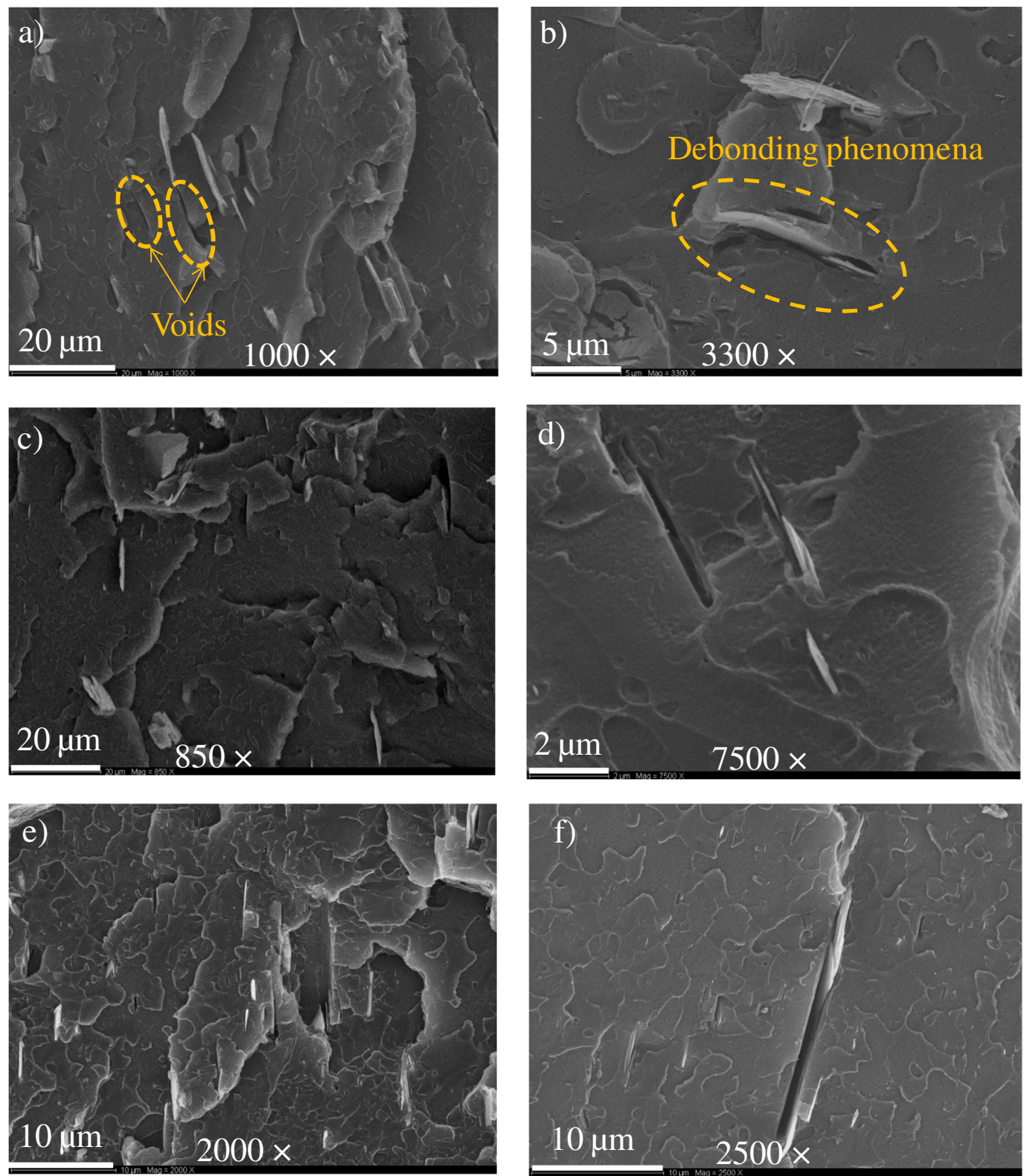

Fig. 4. SEM micrographs of the fractured surfaces of PMMA/MoS 2 composites containing: (a) and (b) $2.5 \mathrm{wt} \% \mathrm{MoS} 2$, (c) and (d) $5 \mathrm{wt} \% \mathrm{MoS}_{2}$, (e) and (f) $10 \mathrm{wt} \% \mathrm{MoS}_{2}$.

particles in the PMMA matrix does not contribute to the decrease in the friction coefficient during the test. This result can be linked to the poor adhesion between the PMMA matrix and the $\mathrm{MoS}_{2}$ fillers. Nevertheless, it can be seen that the plot of the PMMA composite with $10 \mathrm{wt} \%$ of $\mathrm{MoS}_{2}$ is constant, with low fluctuations. The particles trapped in the contact area contribute in giving a steady evolution of the friction coefficient.

OSM (Optical Scanning Microscopy) technique is used to qualitatively assess the worn surface texture of the unfilled PMMA specimen. The obtained three dimensions (3D) profile indicates that wear of the neat polymer against the high chromium steel ball was predominantly abrasive (Fig. 8a). Wear losses analysis was based on measurements made with the optical profilometer. Typical two dimensions (2D) profiles of the wear tracks are shown in Figures $8 \mathrm{~b}$ and $\mathrm{c}$ for the unfilled PMMA and PMMA/MoS 2 composite containing $10 \mathrm{wt} \% \mathrm{MoS}_{2}$ respectively. There is no major difference between the $2 \mathrm{D}$ profiles of the two worn surfaces. We can conclude that addition of $\mathrm{MoS}_{2}$ particles to the PMMA matrix does not improve the wear behavior. Due to the poor adhesion between the $\mathrm{MoS}_{2}$ particles and the PMMA matrix, the repeated friction deformation causes continuous extraction of the fillers from the matrix during the test.

Typical evolutions of the friction coefficient with the number of sliding cycles for $\mathrm{PC} / \mathrm{MoS}_{2}$ composites (without coupling agent) containing different wt $\% \mathrm{MoS}_{2}$ are 

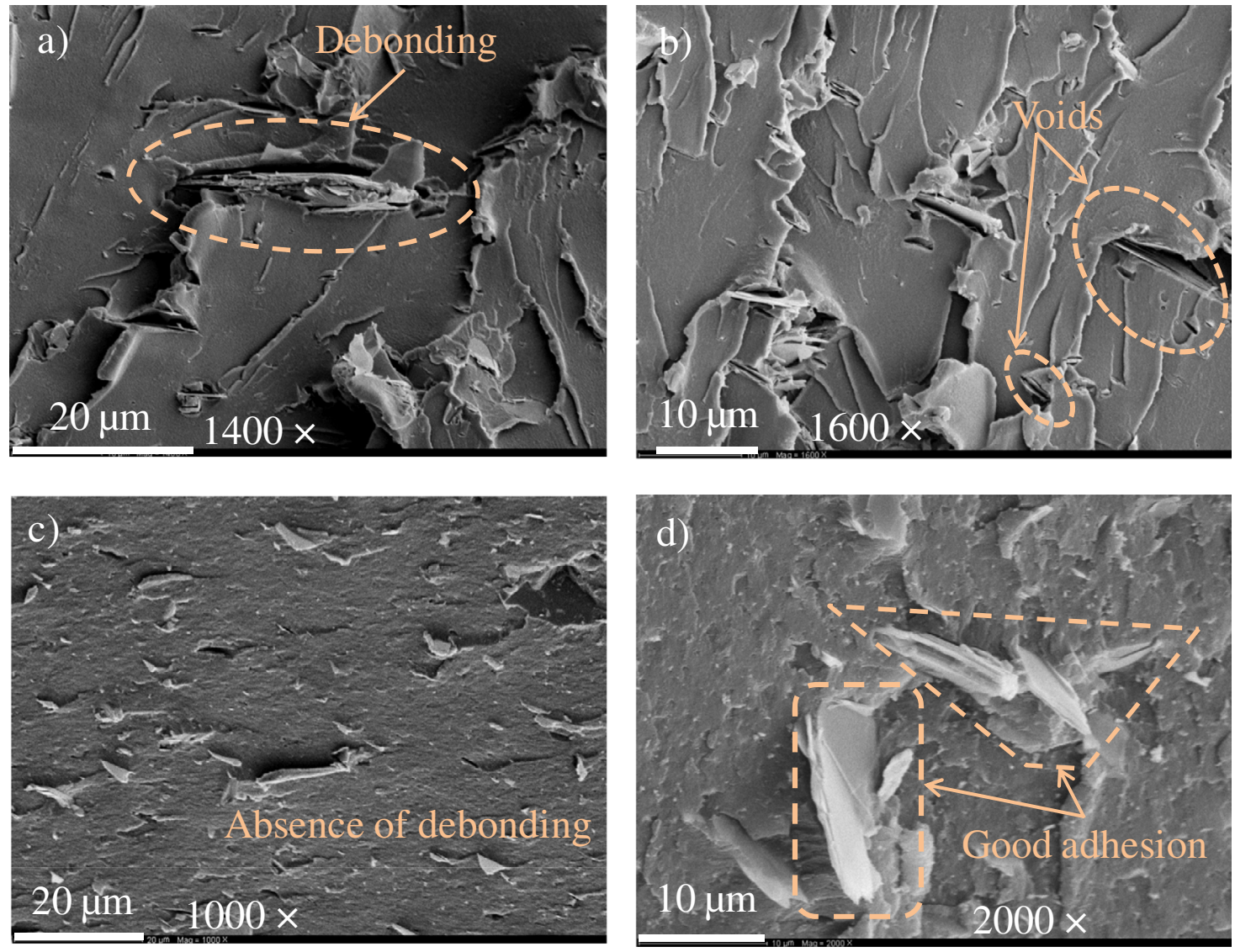

Fig. 5. SEM micrographs of the fractured surfaces of $\mathrm{PC} / \mathrm{MoS}_{2}$ composites containing $10 \mathrm{wt} \% \mathrm{MoS}$; (a) and (b) poor adhesion (without coupling agent), (c) and (d) good adhesion (with coupling agent).

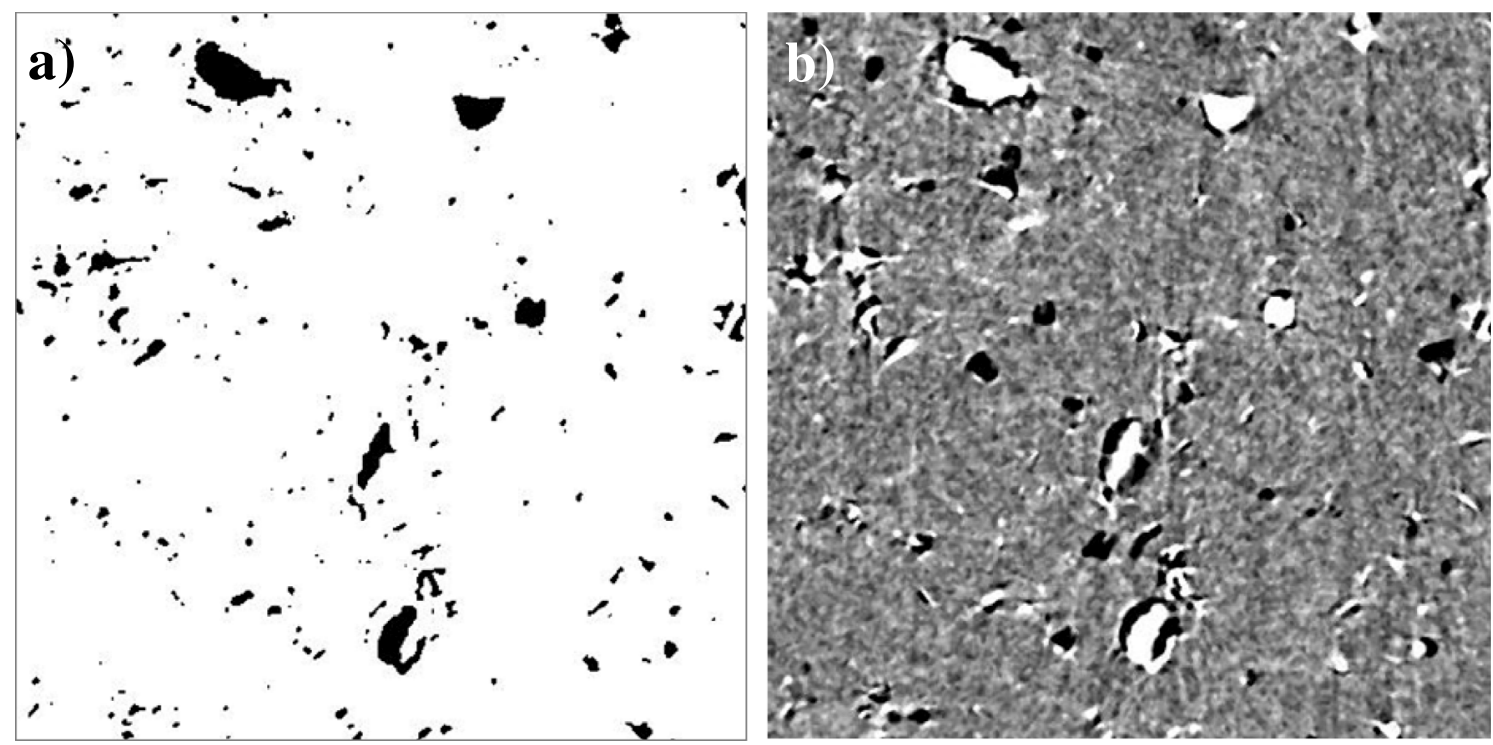

Fig. 6. Two dimensional section of $\mathrm{PMMA} / \mathrm{MoS}_{2}$ composite containing 5 wt $\% \mathrm{MoS}_{2}$ composite; (a) MoS 2 particles only (black), (b) $\mathrm{MoS}_{2}$ particles (white) and porosities (black). 


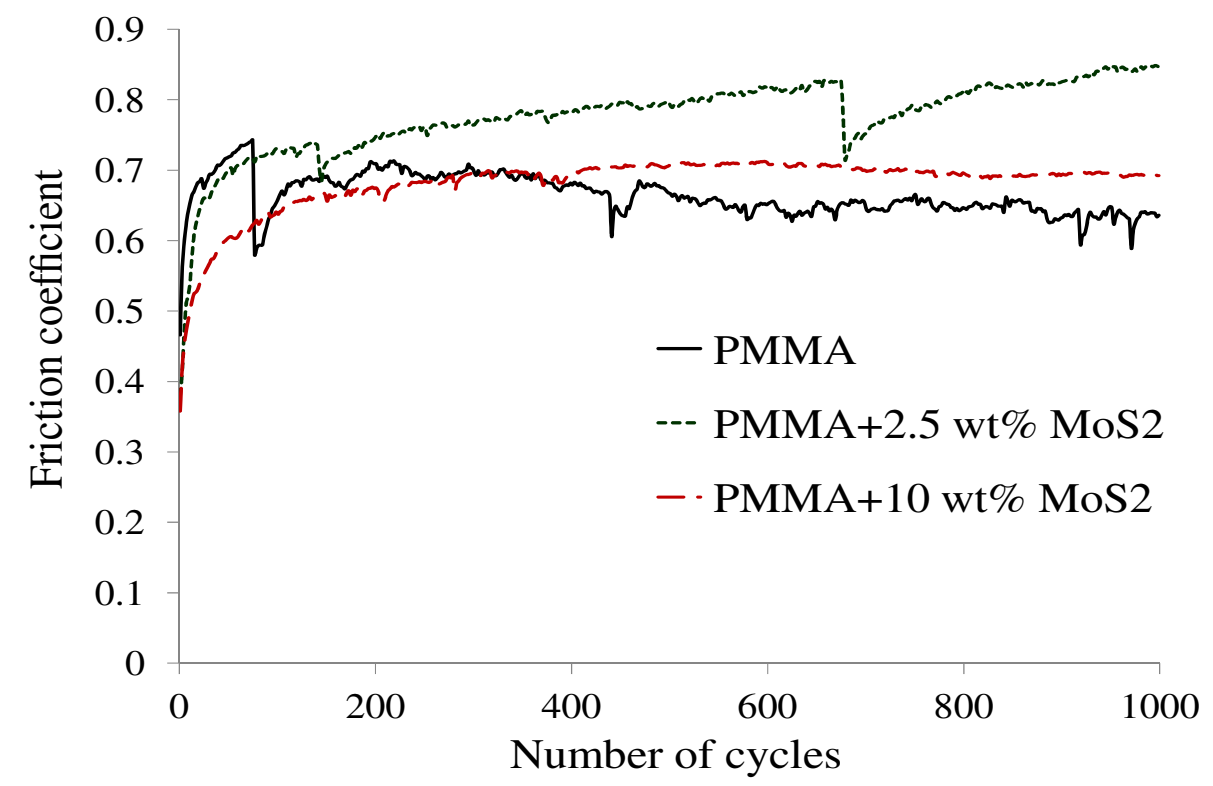

Fig. 7. Typical evolution of the friction coefficient versus the number of cycles for PMMA/MoS 2 composites containing different wt $\% \mathrm{MoS}_{2}$.

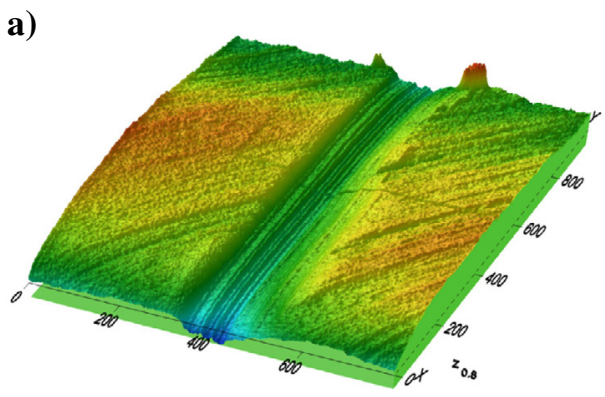

b)

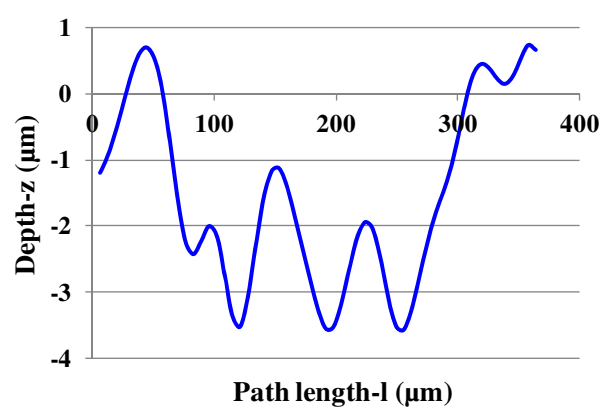

c)

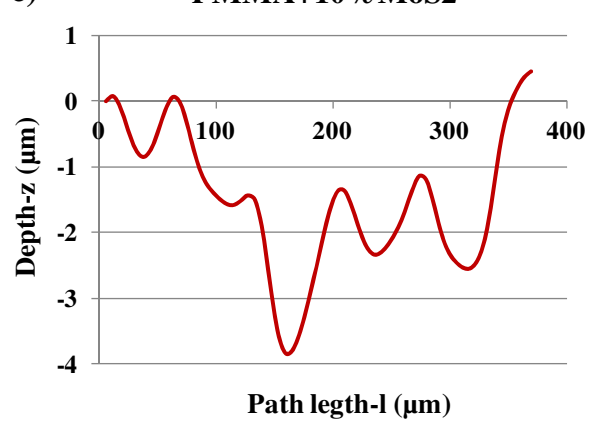

Fig. 8. (a) Three dimensions (3D) profile of the unfilled PMMA worn surface (OSM). Two dimensions (2D) profile of the wear track; (b) unfilled PMMA, (c) PMMA/MoS 2 composite containing $10 \mathrm{wt} \% \mathrm{MoS}_{2}$.

reported in Figure 9. Whatever the wt\% $\mathrm{MoS}_{2}$ is, the evolution of the friction coefficient with the number of sliding cycles shows two main stages. A running-in stage, for which the friction coefficient increases sharply to reach a maximum value after which it decreases gradually. A steady state stage, for which the friction coefficient remains constant as the number of sliding cycles increases. For this last stage, it appears that the stabilized value of the friction coefficient decreases as the wt $\% \mathrm{MoS}_{2}$ increases. Under sliding conditions, the solid lubricant debris is crushed between the polymer and the hard steel counterpart. A third body interface is formed and consequently the wear mechanism changed from solid bodies' friction to dry lubricated friction $[35,36]$. This mechanism is clearly seen in Figure 10. 3D profile of the unfilled PC wear track is obviously rough and not uniform showing 


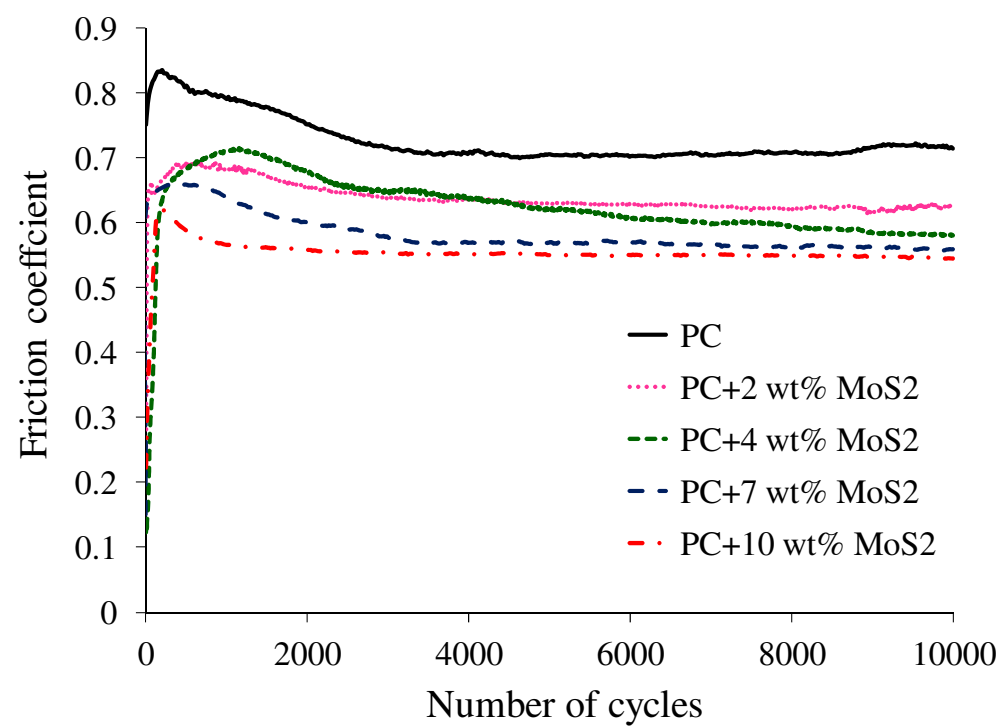

Fig. 9. Typical evolution of the friction coefficient versus the number of cycles for $\mathrm{PC} / \mathrm{MoS}_{2}$ composites containing different wt\% $\mathrm{MoS}_{2}$.

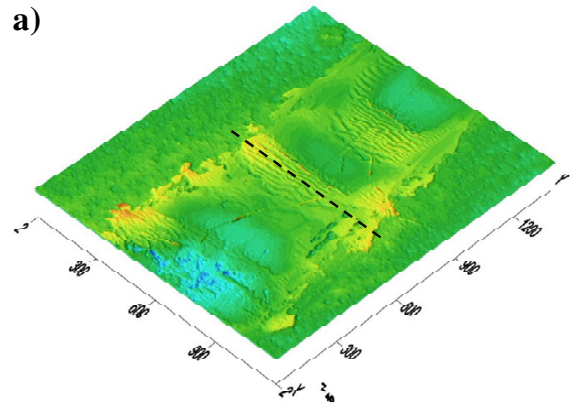

c )

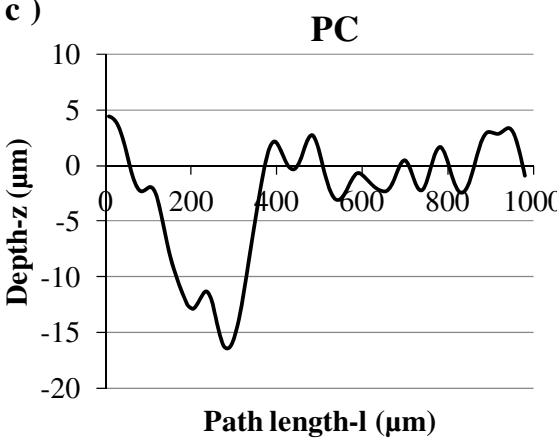

b)

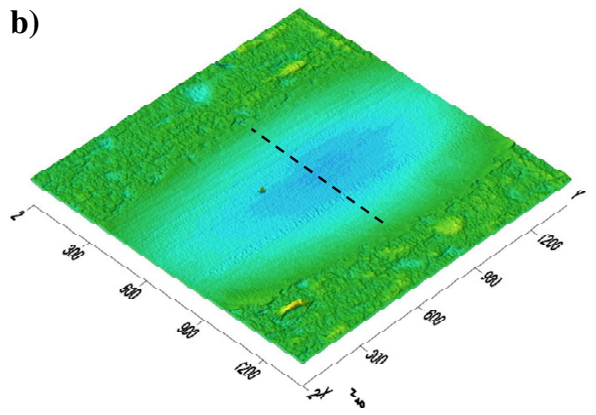

d)

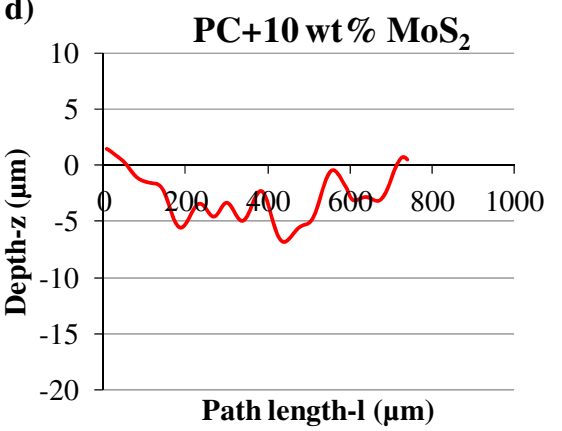

Fig. 10. 3D profiles of the worn surfaces (OSM); (a) unfilled PC, (b) PC/MoS 2 composite containing 10 wt\% MoS $2.2 \mathrm{D}$ profile of the wear track; (c) unfilled PC, (d) PC/MoS 2 composite containing $10 \mathrm{wt} \% \mathrm{MoS}_{2}$.

severe plastic deformation of the neat polymer (Fig. 10a). Nevertheless, Figure 10b indicates that the wear track of $\mathrm{PC} / \mathrm{MoS}_{2}$ composite containing $10 \mathrm{wt} \% \mathrm{MoS}_{2}$ seems to be more uniform and smoother with the presence of light scratches signs of mild abrasive wear mechanism. The typical 2D wear profiles of neat PC compared with that of the PC composite with $10 \mathrm{wt} \%$ of $\mathrm{MoS}_{2}$ are also shown (Figs. 10c and d). Evident positive reliefs can be seen from the plot of the PC wear profile. The positive reliefs are the result of adherent wear debris on the polymer surface. With $10 \mathrm{wt} \%$ of $\mathrm{MoS}_{2}$, the plot of the wear track exhibits almost negative relief. It can be seen also that the width and the depth of the wear track are interestingly smaller than that of neat $\mathrm{PC}$.

\section{Conclusion}

In this study, the tribological behavior of two polymer composites filled with different weight fractions of $\mathrm{MoS}_{2}$ was investigated. Firstly, the PMMA/MoS 2 and $\mathrm{PC} / \mathrm{MoS}_{2}$ composites were mixed using an internal mixer, 
then, the blends were injection molded. Laboratory tests and analysis were performed in order to characterize the composites. Micrographs of the fractured surfaces showed debonding and voids in the case of PMMA/MoS $\mathrm{M}_{2}$ composites. The same features were obtained with $\mathrm{PC} / \mathrm{MoS}_{2}$ composites without coupling agent. Complementary Xray tomography images confirmed the presence of gaps between fillers and matrix. The lack of adhesion could be faced by adding an appropriate coupling agent which improves the interfacial interaction between the solid lubricant fillers and the polymer matrix such as the case of $\mathrm{PC} / \mathrm{MoS}_{2}$ composites. The tribological results of PMMA/MoS 2 composites showed a steady evolution of the friction coefficient at $10 \mathrm{wt} \%$ of $\mathrm{MoS}_{2}$, even if the friction coefficient and the wear losses were not reduced relatively to the unfilled PMMA. The non improvement of the composites wear and friction behaviors was associated with the poor adhesion between the fillers and matrix. Unlike PMMA/MoS 2 composites, the $\mathrm{MoS}_{2}$ powder improves the friction and wear behaviors of $\mathrm{PC} / \mathrm{MoS}_{2}$ composites. The composites filled with $10 \mathrm{wt} \%$ of $\mathrm{MoS}_{2}$ correspond to the best friction coefficient.

\section{References}

[1] H. Voss, K. Friedrich, The wear behavior of short fiber reinforced thermoplastics sliding against smooth steel surfaces, Wear Mater. 16 (1985) 742-750

[2] K. Tanaka, S. Kawakami, Effect of various fillers on the friction and wear of PTFE-based composites, Wear 79 (1982) 221-234

[3] S. Bahadur, D. Gong, J.W. Anderegg, The role of copper compounds as fillers in transfer film formation and wear of nylon, Wear 154 (1992) 207-223

[4] S. Bahadur, The development of transfer layers and their role in polymer tribology, Wear 245 (2000) 92-99

[5] B. Briscoe, L.H. Yoo, T.A. Stolarski, The friction and wear of poly(tetrafluorethylene)-poly(etherketone) composites: an initial appraisal of the optimum, Wear 108 (1986) 357-374

[6] K.H. Hu, J. Wang, S. Schraube, Y.F. Xu, X.G. Huand, R. Stengler, Tribological properties of $\mathrm{MoS}_{2}$ nano-balls as filler in polyoxymethylene-based composite layer of threelayer self-lubrication bearing materials, Wear 266 (2009) 1198-1207

[7] Y. Ye, J. Chen, H. Zhou, An investigation of friction and wear performances of bonded molybdenum disulfide solid film lubricants in fretting conditions, Wear 266 (2009) 859-864

[8] P.Q. La, Q.J. Xue, W.M. Liu, A study of $\mathrm{MoSi}_{2}-\mathrm{MoS}_{2}$ coatings fabricated by SHS casting route, Mater. Sci. Eng. A 277 (2000) 266-273

[9] Y.W. Bae, W.Y. Lee, T.M. Besmann, C.S. Yust, P.J. Blau, Preparation and friction characteristics of selflubricating $\mathrm{TiN}-\mathrm{MoS}_{2}$ composite coatings, Mater. Sci. Eng. A 209 (1996) 372-376

[10] N. Hiraoka, Wear life mechanism of journal bearings with bonded $\mathrm{MoS}_{2}$ film lubricants in air and vacuum, Wear 249 (2002) 1014-1020
[11] C. Langlade, B. Vannes, M. Taillandier, M. Pierantoni, Fretting behavior of low-friction coatings: contribution to industrial selection, Tribol. Int. 34 (2001) 49-56

[12] J.F. Carton, A.B. Vannes, G. Zambelli, L. Vincent, An investigation of the fretting behaviour of low friction coatings on steel, Tribol. Int. 29 (1996) 445-455

[13] C.J. Beall, Solid film lubricants, Metal Finishing 98 (2000) 513-517

[14] K. Miyoshi, Durability evaluation of selected solid lubricating films, Wear 251 (2001) 1061-1067

[15] R. Gadow, D. Scherer, Composite coatings with dry lubrication ability on light metal substrates, Surface and Coatings Technology 151 (2002) 471-477

[16] J. Xu, M.H. Zhu, Z.R. Zhou, Ph. Kapsa, L. Vincent, An investigation on fretting wear life of bonded $\mathrm{MoS}_{2}$ solid lubricant coatings in complex condition, Wear 255 (2003) 253-358

[17] V. Fridrici, S. Fouvry, P. Kapsa, P. Perruchaut, Impact of contact size and geometry on the lifetime of a solid lubricant, Wear 255 (2003) 875-882

[18] S. Bahadur, D. Gong, The action of fillers in the modification of the tribological behavior of polymers, Wear 158 (1992) 41-58

[19] V. Pettarin, M.J. Churruca, D. Felhös, J. Karger-Kocsis, P.M. Frontini, Changes in tribological performance of high molecular weight high density polyethylene induced by the addition of molybdenum disulphide particles, Wear 269 (2010) 31-45

[20] X. Dangsheng, Lubrication behavior of Ni-Cr-based alloys containing MoS2 at high temperature, Wear 251 (2001) 1094-1099

[21] S.M. Aouadi, Y. Paudel, W.J. Simonson, Q. Ge, P. Kohli, C. Muratore, A.A. Voevodin, Tribological investigation of adaptive Mo2N/MoS2/Ag coatings with high sulfur content, Surf. Coatings Technol. 203 (2009) 1304-1309

[22] J. Bijwe, J. John Rajesh, A. Jeyakumar, A. Ghosh, U.S. Tewari, Influence of solid lubricants and fibre reinforcement on wear behaviour of polyethersulphone, Tribol. Int. 33 (2000) 697-706

[23] J. Bijwe, C.M. Logani, U.S. Tewari, Influence of fillers and fibre reinforcement on abrasive wear resistance of some polymeric composites, Wear 138 (1990) 77-92

[24] W. Liu, C. Huang, L. Gao, J. Wang, H. Dang, Study of the friction and wear properties of $\mathrm{MoS}_{2}$-filled nylon 6 , Wear 151 (1991) 111-118

[25] Z. Jin, K.P. Pramoda, G. Xu, S.H. Goh, Dynamic mechanical behavior of melt-processed multi-walled carbon nanotube/poly(methyl methacrylate) composites, Chem. Phys. Lett. 337 (2001) 43-47

[26] R.P. Brown, Fractography and failure mechanisms of polymers and composites: By A. C. Roulin-Moloney. Elsevier Science Publishers, London, 1989, pp $540+$ xix. ISBN 1-85166-296-0, Polymer Testing 10 (1991) 79

[27] G.E. Morris, Determining fracture directions and fracture origins on failed graphite/epoxy surfaces in nondestructive evaluation and flow criticality for composite materials, In: R.B. Pipes, Ed., ASTM STP, American Society for Testing and Materials STP 696, Philadelphia, 1979, pp. 274-297 
[28] D. Purslow, Some fundamental aspects of composites Fractography, Compos. 12 (1981) 241-247

[29] J. Vlassenbroeck, M. Diericka, B. Masschaele, V. Cnudde, L. Van Hoorebeke, P. Jacobs, Software tools for quantification of X-ray microtomography at the UGCT, Nuclear Instruments and Methods in Physics Research A 580 (2007) 442-445

[30] Hattotuwa G.B. Premalal, H. Ismail, A. Baharin, Comparison of the mechanical properties of rice husk powder filled polypropylene composites with talc filled polypropylene composites, Polymer Testing 21 (2002) 833-839

[31] N. Othman, H. Ismail, M. Mariatti, Effect of compatibilisers on mechanical and thermal properties of bentonite filled polypropylene composites, Polym. Degradation and Stability 91 (2006) 1761-1774

[32] C.C. Chamis, Composite Materials, ed. by E.P. Plueddemann, New York, 6, 1974
[33] N. Phueakbuakhao, W. Prissanaroon-Ouajai, N. KreuaOngarjnukool, Effect of coupling agents on mechanical properties and morphology of $\mathrm{CaCO}_{3}$-filled Recycled high density polyethylene, J. Metals Mat. Minerals 18 (2008) $131-135$

[34] K. Yang, Q. Yang, G. Li, Y. Sun, D. Feng, Morphology and mechanical properties of polypropylene/calcium carbonate nanocomposites, J. Mater. Lett. 60 (2006) 805809

[35] B. Ben Difallah, M. Kharrat, M. Dammak, G. Monteil, Mechanical and tribological response of ABS polymer matrix filled with graphite powder, Materials and Design 34 (2012) 782-787

[36] X.-R. Zhang, X.-Q. Pei, Q.-H. Wang, Friction and wear studies of polyimide composites filled with short carbon fibers and graphite and micro $\mathrm{SiO}_{2}$, Materials and Design 30 (2009) 4414-4420 